\title{
Surgery methods and soft tissue extension are the potential risk factors of local recurrence in giant cell tumor of bone
}

Dongqi Li ${ }^{1+}$, Jinlei Zhang ${ }^{1,2+}, \mathrm{Yi} \mathrm{Li}^{3 \dagger}$, Junfeng Xia ${ }^{1 \dagger}$, Yihao Yang ${ }^{1 \dagger}$, Mingyan Ren ${ }^{1}$, Yedan Liao ${ }^{1}$, Shunling Yu', Xiaojuan $\mathrm{Li}^{1}$, Yan Shen ${ }^{1}$, Ya Zhang ${ }^{1}$ and Zuozhang Yang ${ }^{1 *}$

\begin{abstract}
Background: Various treatments of giant cell tumor of bone (GCTB) included in curettages and resections and with adjuvant are exerted, but the best treatment is controversial. The aim of the study was the identification of individual risk factors after various treatments in GCTB.

Methods: A total of 179 patients treated for GCTB between 1998 and 2010 were concluded in the retrospective study. All patients were treated with intralesional curettage, extensive curettage, or wide resection. Mean follow-up was $60.2 \pm 18.7$ months (36 112 months). Age, gender, tumor location, Campanacci grade, soft tissue extension, pathological features, and surgical methods were performed to univariate Kaplan-Meier survival analysis and multivariate Cox regression analysis.

Results: The local recurrence rates of intralesional curettage (41.9\%) and extensive curettage (19.0\%) were significantly higher than that of wide resection $(7.7 \%)$. The higher risk of local recurrence was found for soft tissue extension (hazard $=7.921,95 \% \mathrm{Cl}$ 1.107 56.671), compared with no statistical significances between gender, location, Campanacci grade, pathologic fracture, and local recurrences, which were shown by Kaplan-Meier analysis. However, recurrence-free survival (RFS) of patients younger than 30 was significantly lower than that of patients older than 30. The RFS of pathologic fracture patients with soft tissue extension was significantly lower than that of pathologic fracture patients without soft tissue extension. Multivariate Cox regression analysis indicated that the independent variable that contributed to recurrence-free survival was soft tissue extension and surgical methods. The RFS of extensive curettage had no statistically significant difference with wide resection and was significantly higher than that of intralesional curettage. Use of high-speed burring and bone cement significantly decreased the local recurrence rate.
\end{abstract}

Conclusions: Age (below 30 years), gender, tumor location, Campanacci grade, and pathologic fracture have no statistically significant influence on local recurrences. Soft tissue extension and intralesional curettage of surgical methods increased the RFS. The results of the present study suggested that compared with curettage and wide section, treatment of GCTB by extensive curettage could provide the favorable local control and functional recovery.

Keywords: Intralesional curettage, Extensive curettage, Local recurrence, Recurrence-free survival (RFS)

\footnotetext{
* Correspondence: yangzuozhang@163.com

${ }^{\dagger}$ Equal contributors

'Bone and Soft Tissue Tumors Research Center of Yunnan Province,

Department of Orthopaedics, The Third Affiliated Hospital of Kunming

Medical University (Tumor Hospital of Yunnan Province), Kunming, Yunnan

650118, People's Republic of China

Full list of author information is available at the end of the article
}

C $2016 \mathrm{Li}$ et al. Open Access This article is distributed under the terms of the Creative Commons Attribution 4.0 International License (http://creativecommons.org/licenses/by/4.0/), which permits unrestricted use, distribution, and reproduction in any medium, provided you give appropriate credit to the original author(s) and the source, provide a link to the Creative Commons license, and indicate if changes were made. The Creative Commons Public Domain Dedication waiver (http:// creativecommons.org/publicdomain/zero/1.0/) applies to the data made available in this article, unless otherwise stated. 


\section{Background}

Giant cell tumor of bone (GCTB), or osteoclastoma, is a neoplasm with potential malignancy, accounting for approximately $5 \%$ of all primary bone tumors and typically occurring in the epiphyses of long bones [1, 2]. Generally, GCTB consists of three cell types, mononuclear histiocytic cells, multinucleated giant cells, and neoplastic stromal cells [3], and has been classified into three grades by its histological appearances [4]. However, the clinical and prognostic value of the tumor's grading has been disputed [5-8].

Although histopathological characteristics of most GCTB are benign, some types still have a high rate of local recurrence and the ability to metastasize with a recurrence rate of $2.5-45 \%$ [9-12]. Those cases have postoperative recurrence within 24 months after the surgery $[13,14]$. However, many studies used to show that X-ray grading, pathological fracture, and histological grading have no impact on tumor recurrence, invasiveness, and distant metastasis, which leads to the overlook and underestimation of the recurrence in practice. But with surgical methods being taken into consideration, more and more studies reveal that the recurrence rate of GCTB varies significantly with the factor [15-17] and debates on determining the best one retain for a long period.

It is reported that recurrence rates of GCTB would range from 0 to $65 \%$, depending on the type of treatment and local presentation of the tumor [17-19]. Generally, GCTB is always treated with intralesional curettage and wide resection. The former one has a low risk of invasiveness and can preserve the joint adjacent to the tumor [20], the recurrence rate of which is from 1 to $65 \%[15-18,21]$. Other studies also report lower recurrence rate with the use of polymethylmethacrylate in intralesional curettage; however, the recurrence rate is similar to the result in the study of Blackley et al. and Turcotte et al. without using any adjuvant [16-20]. Wide resection is another recommended surgical therapy when the bone is extensively destructed or possibility to save the adjacent joint is small [22]. Lots of studies have suggested that wide resection contributes to the decrease in the risk of local recurrence as compared with intralesional curettage; moreover, wide resection may increase the recurrence-free survival rate to 84 to $100 \%$ [17-19]. However, the wide resection is associated with higher rates of surgical complications and accompanied by considerable functional impairment.

In the present research, we retrospectively reviewed 179 GCTB patients treated with intralesional curettage, extensive curettage, and wide resection between 1998 and 2010. Recurrence rate was first determined according to different surgical methods. Log-rank test of Kaplan-Meier survival analysis was performed for clinicopathologic features and surgical methods. Multivariate Cox regression was used to analyze the risk factors of local recurrence and determine the best prognostic factors for recurrence.

\section{Methods \\ Patients}

We retrospectively identified 179 patients diagnosed as GCTB from 1998 to 2010 at the Third Affiliated Hospital of Kunming Medical University, including 99 male patients and 80 female patients. The average age of the patients was $32.0 \pm 9.5(13-64)$. The average followup time was $60.2 \pm 18.7$ months (36-112). The visiting intervals were 3 months for the first 2 years after surgeries, 6 months for the third to fifth years, and 12 months for patients after surviving the fifth year. Routine followups included physical examination, X-ray examination, and chest computerized tomography (CT). The patients were not recalled specifically for the study; all the data were retrieved from medical records.

\section{Inclusion and exclusion criteria}

Inclusion criteria covered the following: (1) Benign GCTB was confirmed by histopathological diagnosis according to the 2002 World Health Organization classification of GCTB [23]; (2) Patients had explicit imaging data including X-ray, CT, or magnetic resonance for diagnosis; (3) Patients had the complete records including diagnosis, therapy, follow-up, and recurrence. Exclusion criteria covered the following: (1) malignant GCTB; (2) the follow-up was shorter than 36 months.

\section{Classification of GCTBs}

Levels of GCTBs were graded as grades I, II, and III according to the Campanacci method [15]. In our study, 25 patients were identified as grade I, 78 patients were identified as grade II, and 76 patients were identified as grade III.

\section{Surgery methods of GCTB patients}

Patients enrolled in the present study were treated with intralesional curettage, extensive curettage, and wide resection. Intralesional curettages were performed as a wide cortical window was created to observe the tumor cavity and the tumor tissue was removed with a curette; for extensive curettage, chemical inactivation was performed on the basis of curettage and tumor cavity was packed carefully with autologous, allogenic bone grafts or polymethylmethacrylate (PMMA). According to Campanacci grade, soft tissue extension, and tumor location, the surgical methods of patients were determined. Forty-three patients were treated with curettage, 84 patients were treated with extensive curettage, and 52 patients were treated with wide resection. 


\section{Data collection}

Data were collected from the medical records and included in information on age, gender, tumor location, Campanacci grade, soft tissue extension, pathological fracture, and surgical methods (Table 3).

\section{Ethics}

The project was approved by the Third Affiliated Hospital of Kunming Medical University. The ethics committee approved the relating screening, inspection, and data collection of the patients, and all subjects signed a written informed consent form. All works were undertaken following the provisions of the Declaration of Helsinki.

\section{Statistical analysis}

Differences in the recurrence-free survival between different surgical methods or clinicopathologic features were calculated with log-rank test of Kaplan-Meier survival analysis. Multivariate Cox regression was used to analyze the risk factors of local tumor recurrence. Test of factor interactions was performed to identify potential confounding variables. Statistical analysis was performed using SPSS version 20.0 (IBM, Armonk, NY, USA).

\section{Results}

\section{Local recurrence of patients treated with different surgical methods}

Thirty-eight of 179 patients (21.2\%) had local recurrence of GCTB and the mean time to local recurrence was $16.9 \pm 9.0$ months (5-46 months) (as shown in Table 1). Six cases of recurrence patients were found with pulmonary metastasis (3.4\%), 4 cases had local recurrence and pulmonary metastasis while 2 cases had pulmonary metastasis alone. As shown in Table 1, the patients treated with intralesional curettage had the highest recurrence rate, with 18 of 43 patients (41.9\%) found with local recurrence, while the recurrence rates

Table 1 Local recurrence rate treated with different surgical methods

\begin{tabular}{llll}
\hline Treatment & Total number & Recurrence & $\begin{array}{l}\text { Recurrence } \\
\text { rate (\%) }\end{array}$ \\
\hline Wide resection & 52 & 4 & 7.7 \\
Extension curettage & 84 & 16 & 19.0 \\
Abrasion + bone grafting & 35 & 8 & 22.9 \\
Abrasion + PMMA & 49 & 8 & 16.3 \\
Curettage & 43 & 18 & 41.9 \\
Alcohol & 16 & 6 & 37.5 \\
lodine tincture or $\mathrm{H}_{2} \mathrm{O}_{2}$ & 27 & 12 & 44.4 \\
Total & 179 & 38 & 21.2 \\
\hline
\end{tabular}

$\mathrm{H}_{2} \mathrm{O}_{2}$ hydrogen peroxide, $P M M A$ polymethylmethacrylate of patients treated with extensive curettage and wide resection were only 19.0 and $7.7 \%$, respectively.

\section{RFS analysis in patients by Kaplan-Meier}

There was no significant difference in RFS between different genders, tumor locations, Campanacci grades, or pathological fracture conditions (Fig. 1a-c, f). However, the RFS of patients below 30 years was significantly lower than that of patients older than 30 years (Fig. 1d). And the RFS of patients with soft tissue extension was significantly lower than that of patients without (Fig. 1e). Regarding surgical methods, a different therapy had dramatic difference impact on the RFS (Table 2; Additional file 1: Table S2; Fig. 2) and the pattern was similar to that of the recurrence rate.

\section{Multivariate analysis by Cox regression}

Our results showed that the gender, age, location, Campanacci grade, and pathological fracture had no influence on the recurrence rate. But soft tissue extension would increase the risk of having local recurrence (Table 3). Moreover, wide resection could significantly reduce the local recurrence risk in GCTB patients. And the patients treated with extensive curettage also got lower recurrence risk compared with those treated with curettage (Table 3).

\section{Discussion}

GCTB is a severe type of tumor with a high recurrence rate, strong invasiveness, and complicated biological characteristic. Generally, it is quite difficult to predict the prognosis of the GCTB patients just with the methods of radiology, histology, or other clinical factors.

In the present study, the gender ratio was 1.24 , including 99 male patients and 80 female patients, which was similar to the research of Niu [24]. This value varies significantly in different countries, from 0.8 in USA to 0.5 in Sweden [2]. However, we have found that gender was not a key factor influencing the recurrence-free survival rate of GCTB (Fig. 1a), while patients younger than 30 had a much lower recurrence-free survival rate than patients older than 30, which was indicative of the influence of age on the recurrence rate. This may be a result of the high level of bone metabolism of younger patients $[25,26]$. But the result of Cox regression was opposite to Kaplan-Meier survival analysis and inferred that age was not an independent factor influencing the recurrence. When combined with other factors, it made no impact the recurrence rate of the patients factors (Table 3). The result of univariate Kaplan-Meier analysis was uncorrected on the account of possible confounding variates. To access the association of each variate with recurrence-free survival while controlling for the effects of other variates, multivariate Cox regression was 


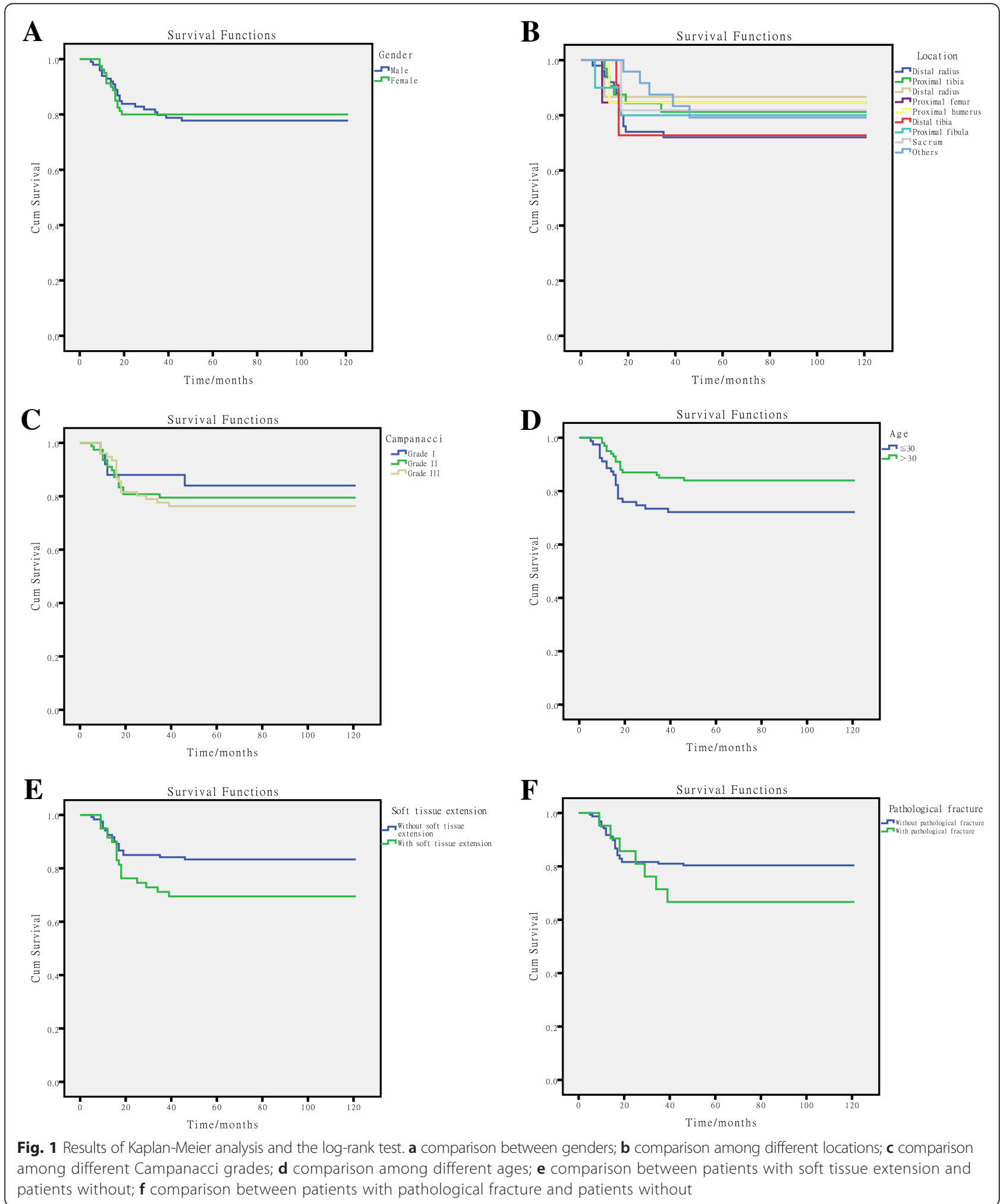

performed. In our study, we found that age was not an independent factor of recurrence after Cox regression correction. Previous studies have also reported that recurrence rate is higher among patients with GCTB at distal radius [2, 18], whereas, according to our data, there was no significant difference among patients with different focus locations (Table 3). Moreover, another widely reported predictive indicator of GCTB, 
Table 2 Recurrence-free estimates at 60 months based on different surgical methods

\begin{tabular}{lll}
\hline Treatment & Recurrence-free survival rate & SE \\
\hline Wide resection & 0.923 & 0.037 \\
Extension curettage & 0.810 & 0.043 \\
Abrasion + bone grafting & 0.771 & 0.071 \\
Abrasion + PMMA & 0.837 & 0.053 \\
Curettage & 0.581 & 0.075 \\
Alcohol & 0.625 & 0.121 \\
lodine tincture or $\mathrm{H}_{2} \mathrm{O}_{2}$ & 0.556 & 0.096 \\
Total & 0.788 & 0.031 \\
\hline
\end{tabular}

SE standard error, $P M M A$ polymethylmethacrylate, $\mathrm{H}_{2} \mathrm{O}_{2}$ hydrogen peroxide

Campanacci grade [27], was also found to have no difference on the recurrence rate of GCTB in our study (Table 3). We thought this might result from the tendency of applying wide resection to high Campanacci grade patients in our study; $57.9 \%$ of patients with grade III and $9 \%$ of patients with grade II were treated with wide resection (Additional file 1: Table S1). We also reported that the pathological fracture conditions of patients had no influence on the recurrence rate (Additional file 1: Table S2). The only clinicopathologic factor contributing to the recurrence rate change was soft tissue extension. There were 25 patients with soft tissue extension in the present study, and the result of multivariate Cox regression is $7.021 \quad(p=0.039)$, indicating the increase of recurrence rate of GCTB due to soft tissue extension. It can be explained that performing the complete removal of tumor tissue is technically difficult and the current lack of applicable local adjuvants after surgery, which eventually leads to the high recurrence rate in GCTB patients with soft tissue extension [28, 29]; some alternative methods are imperative to solve this issue [30,31].

Results of multivariate Cox regression showed that the surgical method was an independent factor influencing the recurrence rate. Among the three types of surgical methods, wide resection had the lowest recurrence rate $(7.7 \%)$ and the recurrence-free survival rate after 60 months was $92.3 \%$. However, restricted by some side effects, wide resection should not be taken as a standard method for GCTB treatment [32]. For curettage method, it has been concluded to have a high recurrence rate $[14,33]$, but our results were inconsistent with the previous studies. Patients treated with iodine tincture or hydrogen peroxide after the surgery had a recurrence rate of $44 \%$, and patients treated with alcohol had an even better prognosis (recurrence rate of $37.5 \%$ ). The difference in the recurrence rates between different adjuvants was not significant (Table 3). For the patients treated with extensive curettage, the two adjuvants, bone grafting and polymethylmethacrylate, both significantly reduce the recurrence rate compared with the curettage method.

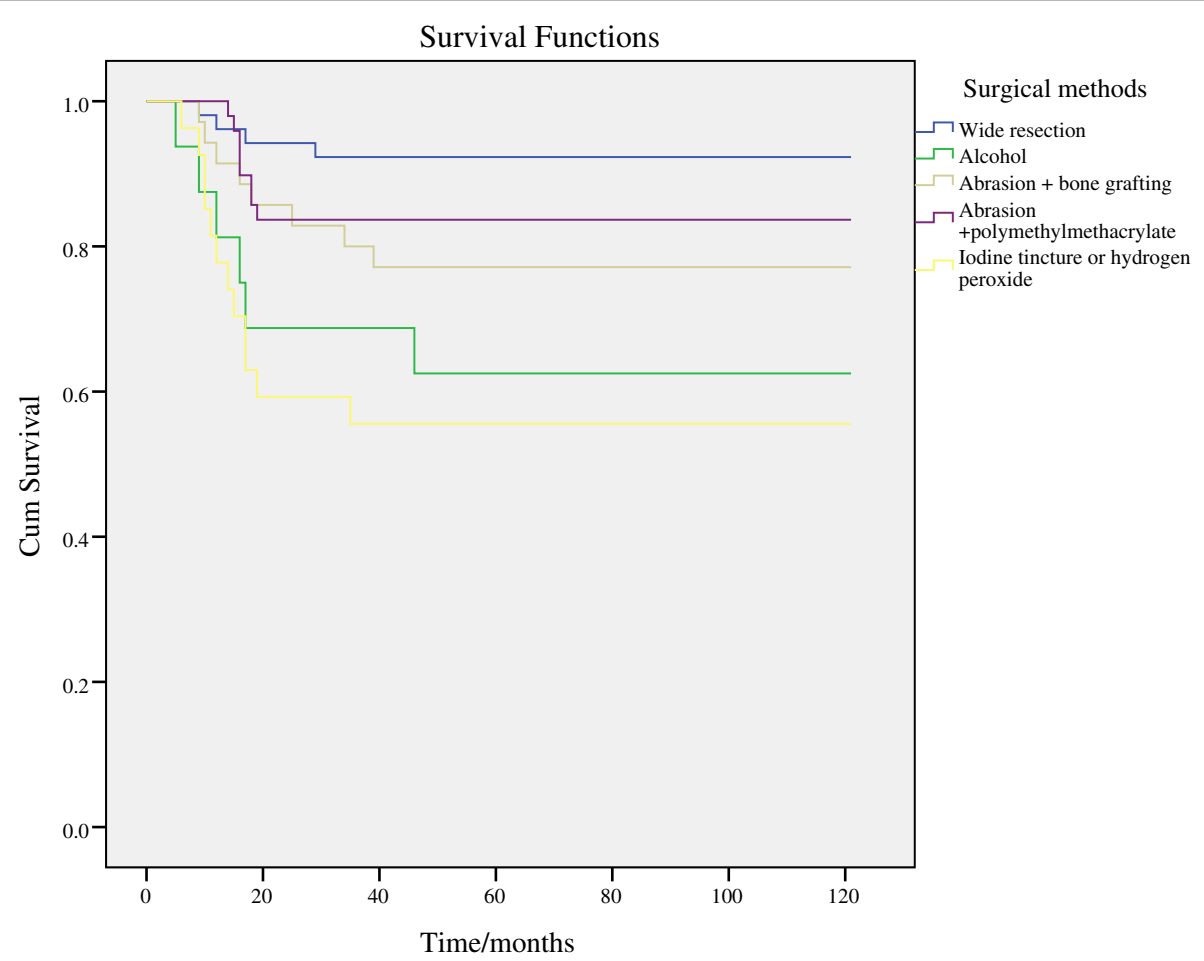

Fig. 2 Kaplan-Meier analysis and the log-rank test among the influence of different surgical methods 
Table 3 Hazard of recurrence in association with multiple factors

\begin{tabular}{|c|c|c|c|}
\hline Parameter & Hazard & $95 \% \mathrm{Cl}$ & $P$ value \\
\hline \multicolumn{4}{|l|}{ Gender } \\
\hline Male & 0.921 & $0.469-1.807$ & 0.810 \\
\hline Female & 1.000 & & \\
\hline \multicolumn{4}{|l|}{ Age } \\
\hline$\leq 30$ & 1.595 & $0.800-3.178$ & 0.185 \\
\hline$>30$ & 1.000 & & \\
\hline \multicolumn{4}{|l|}{ Location } \\
\hline Distal femur & 2.242 & $0.630-7.791$ & 0.212 \\
\hline Proximal tibia & 0.659 & $0.129-3.361$ & 0.616 \\
\hline Distal radius & 2.049 & $0.284-14.766$ & 0.477 \\
\hline Proximal femur & 2.090 & $0.332-13.157$ & 0.432 \\
\hline Proximal humerus & 2.186 & $0.356-13.420$ & 0.398 \\
\hline Distal tibia & 2.736 & $0.593-12.867$ & 0.195 \\
\hline Proximal fibula & 3.325 & $0.501-22.073$ & 0.213 \\
\hline Sacrum & 0.411 & $0.058-2.903$ & 0.373 \\
\hline Others & 1.000 & & 2.2 \\
\hline \multicolumn{4}{|l|}{ Campanacci grade } \\
\hline । & 2.199 & $0.234-20.672$ & 0.491 \\
\hline$\|$ & 3.000 & $0.405-22.196$ & 0.282 \\
\hline III & 1.000 & & \\
\hline \multicolumn{4}{|l|}{ Soft tissue extension } \\
\hline With extension & 7.921 & $1.107-56.671$ & 0.039 \\
\hline Without extension & 1.000 & & \\
\hline \multicolumn{4}{|l|}{ Pathological fracture } \\
\hline With fracture & 1.336 & $0.507-3.517$ & 0.558 \\
\hline Without fracture & 1.000 & & \\
\hline \multicolumn{4}{|l|}{ Treatments } \\
\hline Wide resection & 0.044 & $0.011-0.175$ & 0.000 \\
\hline \multicolumn{4}{|l|}{ Extension curettage } \\
\hline Abrasion + bone grafting & 0.144 & $0.044-0.471$ & 0.001 \\
\hline Abrasion + PMMA & 0.113 & $0.034-0.375$ & 0.000 \\
\hline \multicolumn{4}{|l|}{ Curettage } \\
\hline Alcohol & 0.410 & $0.100-1.682$ & 0.216 \\
\hline lodine tincture or $\mathrm{H}_{2} \mathrm{O}_{2}$ & 1.000 & & \\
\hline
\end{tabular}

PMMA polymethylmethacrylate, $\mathrm{H}_{2} \mathrm{O}_{2}$ hydrogen peroxide, $\mathrm{Cl}$ confidence interval

Previous studies attribute the good performance of extensive curettage to the application of abrasion and polymethylmethacrylate. In our study, the local recurrence rate of wide resection was significantly lower than that of intralesional curettage and extensive curettage (Table 1), and the recurrence-free survival rate of intralesional curettage was significantly lower than that of wide resection and extensive curettage (Additional file 1: Table S2). It indicated that wide resection and extensive curettage treatment were more applicable to patients than intralesional curettage based on lower recurrence rate and higher recurrence-free survival rate. However, wide resection treatment frequently causes serious complications including functional impairment of the extremities. There was no significance of recurrence-free survival rate between wide resection and extensive curettage (Additional file 1: Table S2). Taken together, extensive curettage should be a feasible and effective treatment for GCTB patients.

There were limitations in this study. Firstly, there was a lack of the detailed information of patients recalled or phone interviewed on account of the nature of retrospective data analysis. Secondly, the retrospective study was single center. Thus, the finding should be validated with a prospective, multi-center and larger size sample study, which aims to obtain the feasible and effective treatment for GCTB patients.

\section{Conclusions}

In summary, age, gender, tumor location, Campanacci grade, and pathologic fracture had no statistically significant influence on local recurrences of GCTB. Soft tissue extension and intralesional curettage of surgical methods were independent risk factors of local recurrence of GCTB. The results of the present study suggested that compared with curettage and wide section, treatment of GCTB by extensive curettage could provide the favorable local control and functional recovery. Our study might provide potential guiding significance for the eligible treatment of GCTB in the future.

\section{Additional file}

Additional file 1: Tables S1 and S2. Table S1. Patient demographics. Table S2. Pairwise comparisons for the recurrence-free survival rate of different surgical methods. (DOC $65 \mathrm{~kb}$ )

\section{Abbreviations}

Cl: confidence interval; CT: computerized tomography; GCTB: giant cell tumor of bone; $\mathrm{H}_{2} \mathrm{O}_{2}$ : hydrogen peroxide; PMMA: polymethylmethacrylate;

RFS: recurrence-free survival; SE: standard error.

\section{Competing interests}

The authors declare that they have no competing interests.

\section{Authors' contributions}

The experiment was designed by ZY. The patients' information was collected by $Y Z, D L$, and JX. The literatures were searched by MR, Y Liao, SY, XL, YS, and $Y Z$. The data were analyzed by $Y Y$ and $J Z$, and the draft was written by $Z Y, D L, Y L i$, and JX. All authors read and approved the final manuscript.

\section{Acknowledgements}

Not applicable.

\section{Author details}

${ }^{1}$ Bone and Soft Tissue Tumors Research Center of Yunnan Province, Department of Orthopaedics, The Third Affiliated Hospital of Kunming 
Medical University (Tumor Hospital of Yunnan Province), Kunming, Yunnan 650118, People's Republic of China. ${ }^{2}$ Department of Orthopedics, Zhoukou City Central Hospital, The Affiliated Hospital of Xinxiang Medical College, Zhoukou 466000, People's Republic of China. ${ }^{3}$ Department of Oncology, Kunming General Hospital of Chengdu Military Command, Kunming, Yunnan 650118, People's Republic of China.

Received: 10 June 2015 Accepted: 12 April 2016

Published online: 19 April 2016

\section{References}

1. Faisham WI, Zulmi W, Halim AS, Biswal BM, Mutum SS, Ezane AM. Aggressive giant cell tumour of bone. Singapore Med J. 2006;47:679-83.

2. Rockberg J, Bach BA, Amelio J, Hernandez RK, Sobocki P, Engellau J, Bauer HCF, Liede A. Incidence trends in the diagnosis of giant cell tumor of bone in Sweden since 1958. J Bone Joint Surg Am. 2015;97:1756-66.

3. Werner M. Giant cell tumour of bone: morphological, biological and histogenetical aspects. Int Orthop. 2006;30:484-9.

4. Turcotte RE. Giant cell tumor of bone. Orthop Clin N Am. 2006;37:35-51.

5. Lackman RD, Hosalkar HS, Ogilvie CM, Torbert JT, Fox EJ. Intralesional curettage for grades II and III giant cell tumors of bone. Clin Orthop Relat Res. 2005;438:123-7.

6. Wang H, Wan N, Hu Y. Giant cell tumour of bone: a new evaluating system is necessary. Int Orthop. 2012;36:2521-7.

7. Chen J, Younusi A, Cao L, Xu L, Zhou Y, Zhen T, Song X. Serum levels of NTx and TRACP5b in giant cell tumor of bone and its clinical implications. Clin Lab. 2015:61:1077-81.

8. Dong $Z$, Long $\mathrm{M}, \mathrm{Li} \mathrm{H}, \mathrm{Fu}$ Y, Chen $\mathrm{H}$. The relationship between surgical staging, pathologic grading, operative type and postoperative recurrence in giant cell tumor of bone. Hunan Yi Ke Da Xue Xue Bao. 1999;24:174-6.

9. McGough RL, Rutledge J, Lewis VO, Lin PP, Yasko AW. Impact severity of local recurrence in giant cell tumor of bone. Clin Orthop Relat Res. 2005;438:116-22.

10. Muheremu A, Niu X. Pulmonary metastasis of giant cell tumor of bones. World J Surg Oncol. 2014;12:261.

11. Szendröi M. Giant-cell tumour of bone. J Bone Joint Surg (Br). 2004;86:5-12.

12. Chang SS, Suratwala SJ, Jung KM, Doppelt JD, Zhang HZ, Blaine TA, Kim TW, Winchester RJ, Lee FY-I. Bisphosphonates may reduce recurrence in giant cell tumor by inducing apoptosis. Clin Orthop Relat Res. 2004;426:103-9.

13. Balke M, Ahrens H, Streitbuerger A, Koehler G, Winkelmann W, Gosheger G, Hardes J. Treatment options for recurrent giant cell tumors of bone. J Cancer Res Clin Oncol. 2009;135:149-58.

14. Su YP, Chen WM, Chen TH. Giant-cell tumors of bone: an analysis of 87 cases. Int Orthop. 2004;28:239-43.

15. Campanacci M, Baldini N, Boriani S, Sudanese A. Giant-cell tumor of bone. J Bone Joint Surg Am. 1987;69:106-14.

16. Singh AS, Chawla NS, Chawla SP. Giant-cell tumor of bone: treatment options and role of denosumab. Biogeosciences. 2015;9:69-74.

17. Becker W, Dohle J, Bernd L, Braun A, Cserhati M, Enderle A, Hovy L, Matejovsky Z, Szendroi M, Trieb K. Local recurrence of giant cell tumor of bone after intralesional treatment with and without adjuvant therapy. J Bone Joint Surg Am. 2008;90:1060-7.

18. Balke M, Schremper L, Gebert C, Ahrens H, Streitbuerger A, Koehler G, Hardes J, Gosheger G. Giant cell tumor of bone: treatment and outcome of 214 cases. J Cancer Res Clin Oncol. 2008;134:969-78.

19. Bergovec M, Petkovic M, Smerdelj M, Seiwerth S, Brkic L, Robert K, Orlic D. Giant cell tumor of bone: results and treatment complications. Acta Med Croatica. 2014;68:405-10.

20. Kivioja AH, Blomqvist C, Hietaniemi K, Trovik C, Walloe A, Bauer HC, Jorgensen PH, Bergh P, Follerås $\mathrm{G}$. Cement is recommended in intralesional surgery of giant cell tumors: a Scandinavian Sarcoma Group study of 294 patients followed for a median time of 5 years. Acta Orthop. 2008;79:86-93.

21. Malek F, Krueger P, Hatmi Z, Malayeri A, Faezipour H, O'Donnell R. Local control of long bone giant cell tumour using curettage, burring and bone grafting without adjuvant therapy. Int Orthop. 2006;30:495-8.

22. Gosal GS, Boparai A, Makkar GS. Long-term outcome of endoprosthetic replacement for proximal femur giant cell tumor. Niger J Surg. 2015;21:143-5.

23. Fletcher CD, Unni KK, Mertens F. Pathology and genetics of tumours of soft tissue and bone. World Health Organization classification of tumours 2013.
24. Niu X, Zhang Q, Hao L, Ding Y, Li Y, Xu H, Liu W. Giant cell tumor of the extremity: retrospective analysis of 621 Chinese patients from one institution. J Bone Joint Surg Am. 2012;94:461-7.

25. Niu X, Xu H, Inwards CY, Li Y, Ding Y, Letson GD, Bui MM. Primary bone tumors: epidemiologic comparison of 9200 patients treated at Beijing Ji Shui Tan Hospital, Beijing, China, with 10165 patients at Mayo Clinic, Rochester, Minnesota. Arch Pathol Lab Med. 2015;139:1149-55.

26. DelaGarza-Montano P, Estrada-Villasenor E, Dominguez Rubio R, MartinezLopez V, Avila-Luna A, Alfaro-Rodriguez A, Garciadiego-Cazares D, Carlos A, Hernandez-Perez AD, Bandala C. Epidemiological aspects of osteosarcoma, giant cell tumor and chondrosarcoma musculoskeletal tumors-experience of the National Rehabilitation Institute, Mexico City. Asian Pac J Cancer Prev. 2015;16:6451-5

27. Wang CS, Lou JH, Liao JS, Ding XY, Du LJ, Lu Y, Yan L, Chen KM. Recurrence in giant cell tumour of bone: imaging features and risk factors. Radiol Med. 2013;118:456-64.

28. van der Heijden L, van de Sande MA, Dijkstra PD. Soft tissue extension increases the risk of local recurrence after curettage with adjuvants for giant-cell tumor of the long bones. Acta Orthop. 2012;83:401-5.

29. van der Heijden L, Dijkstra PS, Campanacci DA, Gibbons CMH, van de Sande MA. Giant cell tumor with pathologic fracture: should we curette or resect? Clin Orthop Relat Res. 2013:471:820-9.

30. Kostenuik PJ, Nguyen HQ, McCabe J, Warmington KS, Kurahara C, Sun N, Chen C, Li L, Cattley RC, Van G. Denosumab, a fully human monoclonal antibody to RANKL, inhibits bone resorption and increases BMD in knock-in mice that express chimeric (murine/human) RANKL. J Bone Miner Res. 2009;24:182-95

31. Ueda T, Morioka H, Nishida $Y$, Kakunaga S, Tsuchiya H, Matsumoto $Y$, Asami $Y$, Inoue T, Yoneda T. Objective tumor response to denosumab in patients with giant cell tumor of bone: a multicenter phase II trial. Ann Oncol. 2015;26:2149-54.

32. van der Heijden L, Dijkstra PD, van de Sande MA, Kroep JR, Nout RA, van Rijswijk CS, Bovee JV, Hogendoorn PC, Gelderblom H. The clinical approach toward giant cell tumor of bone. Oncologist. 2014;19:550-61.

33. Rajani R, Schaefer $L$, Scarborough MT, Gibbs CP. Giant cell tumors of the foot and ankle bones: high recurrence rates after surgical treatment. J Foot Ankle Surg. 2015:54:1141-5.

\section{Submit your next manuscript to BioMed Central and we will help you at every step:}

- We accept pre-submission inquiries

- Our selector tool helps you to find the most relevant journal

- We provide round the clock customer support

- Convenient online submission

- Thorough peer review

- Inclusion in PubMed and all major indexing services

- Maximum visibility for your research

Submit your manuscript at www.biomedcentral.com/submit
C Biomed Central 